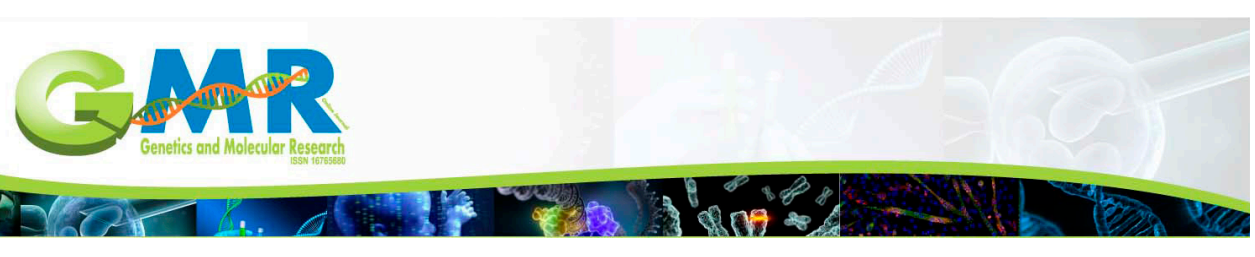

\title{
Path analysis of agro-industrial traits in sweet sorghum
}

\author{
G.M.R. Lombardi', J.A.R. Nunes ${ }^{1}$, R.A.C. Parrella ${ }^{2}$, D.H.L. Teixeira ${ }^{1}$, A.T. Bruzi ${ }^{3}$, \\ N.N.L. Durães ${ }^{4}$ and T.G. Fagundes ${ }^{1}$ \\ ${ }^{1}$ Departamento de Biologia, Universidade Federal de Lavras, Lavras, MG, Brasil \\ ${ }^{2}$ Embrapa Milho e Sorgo, Sete Lagoas, MG, Brasil \\ ${ }^{3}$ Departamento de Agricultura, Universidade Federal de Lavras, Lavras, MG, Brasil \\ ${ }^{4}$ Departamento de Biologia, Universidade Norte Fluminense Darcy Ribeiro, \\ Campos dos Goytacazes, Rio de Janeiro, RJ, Brasil \\ Corresponding author: G.M.R. Lombardi \\ E-mail: gabriellelombardi@hotmail.com
}

Genet. Mol. Res. 14 (4): 16392-16402 (2015)

Received January 30, 2015

Accepted August 11, 2015

Published December 9, 2015

DOI http://dx.doi.org/10.4238/2015.December.9.8

ABSTRACT. Sweet sorghum has considerable potential for ethanol production due to its succulent stalks that contain directly fermentable sugars. Since many traits need to be considered in the selection process to breed superior cultivars for ethanol production, then correlations between the traits might be of use to help the breeder define optimal improvement strategies. The aim of this study was to investigate the association between the principal agro-industrial traits in sweet sorghum, and to evaluate the direct and indirect effects of primary and secondary traits on ethanol production per hectare. In total, 45 sweet sorghum genotypes (lineage/ hybrids) were evaluated in an experiment designed in an alpha lattice 5 $x 9$. The data were analyzed using a mixed model approach. A detailed study of simple correlations was accomplished using path analysis. The experimental precision was high, with an accuracy above $76 \%$. The various genotypes showed genetic variation for all agronomic and industrial traits, except stalk diameter. Some agro-industrial traits showed significant simple 
correlations with ethanol production, but according to the path analysis, some of these traits did not show a significant direct or indirect effect on ethanol production. The results highlighted the primary and secondary traits with practical relevance to sweet sorghum breeding, since they showed director indirect effects on ethanol production.

Key words: Sorghum bicolor, Ethanol production; Correlation; Path analysis

\section{INTRODUCTION}

Since 2008, the Brazilian market has had an increasing gap between the effective supply and the potential demand for ethanol. One of the factors that has caused the rise in demand has been the increased sale of flex automobiles that, according to Energy Research Company data (EPE, 2011), rose by approximately $11 \%$ per year between 2008 and 2010. In contrast, ethanol supply has remained practically constant in the same period. While 27.1 billion liters were produced in 2008 , production in 2010 was 27.9 billion liters, an increase of only $1.5 \%$ per year (EPE, 2011). According to Milanez et al. (2012), the ethanol deficit will likely increase to 12 billion liters and will inevitably result in an increase in the price of ethanol.

Ethanol production in Brazil is dependent on sugarcane. However, new sources must be found to meet the demand. In this context, an interesting alternative crop for ethanol production is sweet sorghum, Sorghum bicolor (L.) Moench (Kim and Day, 2010; Regassa et al., 2014). Sweet sorghum has succulent stalks with directly fermentable sugars, and can be processed using the established agro-industrial infrastructure for the production of ethanol. Additionally, sweet sorghum can be grown and processed during the sugarcane off-season, reducing both the period of inactivity of the extraction industries and the fluctuations in the price of ethanol throughout the year.

Sweet sorghum breeding programs are in place to obtain superior cultivars for ethanol production. Since many agronomic and industrial traits are related to ethanol production, it is necessary to determine the correlated ness of these traits to help breeders establish better selection strategies in their breeding programs.

Correlation estimates enable the evaluation of the behavior of one or more trait susing the behavior of another trait, i.e., they provide a means to estimate the potential consequences of selection. Thus, a comprehensive understanding of inter-trait correlations may make it feasible to carry out indirect selection. This latter approach might be particularly important for trait(s) that are not easily measured or are associated with low heritability (Carvalho and Cruz, 1996).

Although correlation information is key in plant breeding, each analysis is restricted to a pair of traits. Additionally, simple correlation estimates may not represent the actual association between two traits, since there may be interference by a third trait, or group of traits, that might distort the correlation estimates (Wright, 1921).

Wright (1921) proposed that the limitation of simple correlation analyses might be avoided using Path Analysis. This approach allows a more practical study of the association between groups of traits by the breakdown of the simple correlation coefficients into direct and indirect effects of a group of traits over a basic or main variable.

Path analysis has been widely used in the breeding of crops such as açai palm (Singh et al., 2005; Espósito et al., 2012; Teixeira et al., 2012) and popcorn (Mundim et al., 2013). However, relatively little use of the method has been made in sweet sorghum (Kumar et al., 2012). The use 
of path analysis should enable the acquisition of knowledge on the relationships among the main agro-industrial traits in sweet sorghum in order to provide the necessary information to establish the optimal breeding program strategies. In this study, we performed a path analysis study to evaluate the associations between agro-industrial traits in sweet sorghum; this analysis enabled the breakdown of phenotypic correlations into direct and indirect effects on the rate of ethanol production.

\section{MATERIAL AND METHODS}

The experiment was conducted at the Center of Scientific and Technological Development in Agriculture - Muquémof the Federal University of Lavras - UFLA, located at Lavras city, Minas Gerais State, Brazil, at an altitude of $918 \mathrm{~m}$, latitude $21^{\circ} 14^{\prime} \mathrm{S}$, longitude $45^{\circ} \mathrm{O} 0^{\prime} \mathrm{W}$.

A total of 45 genotypes from the Sweet Sorghum Germplasm Bank of Embrapa Milho e Sorgo located at Sete Lagoas, Minas Gerais State, were evaluated; the selected genotypes included 10 restorer lines, three male-sterile lines and 32 hybrids.

The genotypes were evaluated in an experiment designed in a $5 \times 9$ alpha-lattice, with three replicates, in an area under minimal cultivation. Each replicate constituted nine blocks with five plots. Experimental plots consisted of two rows of $5.0 \mathrm{~m}$, spaced 0.6 map art. Sowing was carried out in November 2012. Fertilizers were applied at a rate of $400 \mathrm{~kg} / \mathrm{ha}$ of NPK (08-2816) during sowing. Thinning was performed 15 days after plant emergence. The plant population density was 140,000 plants/ha.

The experiment was conducted under natural rainfall conditions without supplemental irrigation. At 30 days after sowing, $200 \mathrm{~kg} / \mathrm{ha}$ urea was applied. Weed control was performed using an atrazine-based herbicide ( $3.0 \mathrm{~L} / \mathrm{ha}$ ) supplemented by mechanical control when needed. When necessary, insect pest and disease control was carried out following the recommendations for the crop in that region. Harvest was performed manually at an average of 125 days after sowing.

Various agronomic traits were measured: Flowering (FLOWER) - the number of days from sowing to approximately $50 \%$ of the plants in the plot in flower. Plant height $(\mathrm{PH})$ - average height $(\mathrm{m})$ of eight plants at random in each plot; this was measured from the soil surface to the apex of the panicle. Stalk diameter (SD) - average diameter $(\mathrm{mm})$ of eight plants at random in each plot; this was measured in the 4th internode from the base. Panicle mass (PM) - average panicle mass $(\mathrm{m})$ of eight plants at random in each plot. Tons of stalk per hectare (TSH) - all plants in the plot (whole plant without leaves and panicle) were weighed in $\mathrm{kg}$ with a digital hanging scale; the data were expressed in tons per hectare.

Industrial and technological traits were also measured: Juice extraction (EXT) - eight plants per plot without leaves and panicles were randomly sampled; the juice was extracted from a subsample of $500 \pm 0.5 \mathrm{~g}$ in a hydraulic press, with a minimum and constant pressure of 250 $\mathrm{kgf} / \mathrm{cm}^{2} \mathrm{on}$ the sample, for a period of one minute. The values obtained from the extraction were measured by the expression (1):

$$
E X T=\frac{\text { Weight of the juice }}{500} \times 100
$$

The total soluble solid content \% juice (TSS) was determined in filtered juice on paper by a digital refractometer automatic reading with automatic temperature correction and maximum resolution of $0.1^{\circ}$ Brix (AOAC, 1990). The tons of brix per hectare (TBH) were determined from the expression (2): 
Sucrose in \% stalk (POLc) was calculated by expression (3) (CONSECANA, 2006):

$$
P O L c=P O L \times(1-0.01 \times F I B E R C) \times C
$$

where POL is the apparent content of sucrose in \% juice; C is the coefficient of transformation \% juice in \% stalk, and FIBER is the percentage of fiber in the stalk.

The total reducing sugars in \% stalk (RSc) is given by equation (4) (CONSECANA, 2006):

$$
R S c=R S \times(1-0.01 \times F I B E R c) \times C
$$

where RS is the content of total reducing sugars in \% juice. The total recoverable sugars (TRS) represents all the sugar contained in the juice of sorghum in reduced form or as invert sugar. The TRS ( $\mathrm{kg}$ sugar per ton of stalk) is calculated by equation (5) (CONSECANA, 2006):

$$
T R S=(10 \times P O L c \times 1.05263 \times 0.905)+(10 \times R S c \times 0.905) \quad(\text { Equation } 5)
$$

where 1.05263 is the stoichiometric conversion of sucrose into reducing sugar; 0.905 is the coefficient of recovery assuming an industrial loss of $9.5 \%$.

The ethanol production in L/ha (ETP) was estimated by equation (6) (CONSECANA, 2006):

$$
E T P=E T \times F B Y
$$

where ET is the production of hydrous ethanol in L/ton stalk. The data analysis was performed with recovery of interblock information using the mixed model approach by Proc Mixed of SAS Statistical Analysis System (Littel et al., 2006). The residual maximum likelihood method was used to estimate the variance components. The selective accuracy of each experiment was estimated as described in Resende and Duarte (2007).

Phenotypic and environmental correlations between the traits were estimated. The significance of phenotypic correlations was verified via bootstrap, while environmental correlations were tested by the Student $t$-test (Cruz, 2013).

For the path analysis, the phenotypic correlation matrix of the explanatory variables was verified in relation to multicollinearity. The test used was the assessment of the condition number (CN) as proposed by Montgomery and Peck (1981), which examines the ratio between 
the highest and lowest eigen values of the correlation matrix. Multicollinearity is considered low when $\mathrm{CN}<100$, moderate to high if $100<\mathrm{CN}<1000$ and severe if $\mathrm{CN}>100$. When severe multicollinearity was identified, a constant $k$ of 0.05 was added to the main diagonal of the correlation matrix, in a similar manner as in the ridge regression method (Carvalho and Cruz, 1996).

Path analysis was performed using a causal diagram with two chains (Figure 1). The first chain contained the trait ETP as the basic variable and TBH, EXT, POLc, RSc, and TRS as primary explanatory variables. The second chain contained the secondary explanatory variables FLOWER, $\mathrm{PH}, \mathrm{PM}$, and FIBER over the primary variables.



Figure 1. Causal chain diagram of the direct and indirect effects of the secondary variables FLOWER, PH, PM, and FIBER and the primary variables TBH, EXT, POLc, RSc, and TRS on ethanol production (ETP). Unidirectional arrows indicate a direct effect of each explanatory variable, while bi-directional arrows represent interdependence of two explanatory variables.

\section{RESULTS}

\section{Phenotypic and environmental correlations}

Statistical analysis showed that the alpha lattice experimental design had low efficiency; hence, analyses were performed considering a randomized complete block design. Experimental precision was verified through accuracy, which reflects the confidence in the estimation of real 
genotypic values from the phenotypic values. With the exception of stalk diameter, estimated experimental precision was high using the method of Resende and Duarte (2007) with accuracy above $63 \%$ (Tables 1 and 2).

We found a significant difference among the genotypes $(P<0.05)$ for all traits, except stalk diameter (Tables 1 and 2). The presence of genetic variation indicates the possibility of selection gain. These results were also essential for accurate estimation of the correlations, since this parameter measures the joint variation of traits.

Phenotypic correlations varied from -0.91 (POLc - RSc) to 0.99 (TRS - POLc), while environmental correlations varied from -0.9 (POLc - RSc) to 0.99 (TRS - POLc) (Table 3). The correlation estimates were within the expected range (-1 to 1), allowing good inference.

The agronomic traits (FLOWER, PH, and PM) presented low correlations (Table 3).

The negative phenotypic correlation between PM and FLOWER (-0.27) indicates that the selection of plants with later flowering might result in plants with lower panicle mass.

The traits FLOWER and PH presented positive phenotypic correlations with TSH (Table 3 ). This result indicates that taller and later developing plants are associated with higher stalk yield. The traits (FLOWER, PH, and TSH) presented significant phenotypic correlations with some technological traits associated with sugar content and ethanol production per hectare.

In general, fiber content showed low or negligible correlations with other agronomic and technological traits (Table 3). Nevertheless, fiber content showed a negative and significant correlation with percentage of extracted juice $(-0.68)$. Similar results were reported in a study of sugarcane (Bovi and Serra, 2001)

Traits associated with quality of the juice have great relevance for breeding superior cultivars of sweet sorghum. We found that traits related to the quantity of sugar (TSS, TBH, POLc, RSc, and TRS) were strongly positively correlated (Table 3). TSS stood out due to its strong positive phenotypic correlations with TRS (0.98), TBH (0.84), and POLc (0.98). Environmental correlations showed higher positive values $(0.81 ; 0.64$; and 0.80 ; respectively) indicating that environmental factors affect the expression of these traits in the same direction.

Therefore, it is important to determine the magnitude of the correlations of the main agro-industrial traits with ETP. Our analysis showed that FLOWER, TSH, TSS, TBH, POLc, and TRS had high positive correlations with ETP, while RSc had a high negative correlation (Table 3). This outcome is similar to that in studies performed with sugarcane (Chaudhary and Joshi, 2005).

$\begin{aligned} & \text { Table 1. Summary of statistical analysis of agronomic traits used to evaluate } 45 \text { sweet sorghum genotypes grown } \\
& \text { in Lavras city in the 2012/2013 growing season. }\end{aligned}$
\begin{tabular}{lccccc} 
Statistics & FLOWER & PH & SD & PM & TSH \\
\hline$F_{\text {c Genotype }}$ & $5.26^{* *}$ & $8.59^{* *}$ & $1.78^{\text {n.s. }}$ & $1.66^{*}$ & $8.59^{* *}$ \\
Error variance & 10.98 & 0.06 & 2.75 & $35,533.7$ & 44.40 \\
Overall mean & 77 & 2.96 & 13.8 & 476 & 41.2 \\
Mean sterile male & 72.8 & 1.58 & 13.5 & 327.8 & 17.1 \\
Mean without sterile males & 77.56 & 3.05 & 13.8 & 486.9 & 72.9 \\
Accuracy & 0.90 & 0.94 & 0 & 0.63 & 0.94 \\
\hline
\end{tabular}

FLOWER, flowering time (days); PH, plant height (m); SD, stalk diameter (mm); PM panicle mass (g); and TSH, tons of stalk per hectare. *and **indicate significant difference by Snedecor's F-test at 5 and $1 \%$ probability levels, respectively. ${ }^{\text {n.s. }}$ Non-significant by Snedecor's F-test. 
Table 2. Summary of statistical analysis of technological traits used to evaluate phenotypes of 45 sweet sorghum genotypes grown in Lavras city in the 2012/2013 growing season.

\begin{tabular}{|c|c|c|c|c|c|c|c|c|}
\hline Statistics & EXT & TSS & TBH & POLc & RSc & FIBER & TRS & ETP \\
\hline $\mathrm{F}_{\mathrm{c}}$ Genotypes & $2.37^{* *}$ & $4.43^{\star *}$ & $7.40^{* *}$ & $4.43^{\text {** }}$ & $3.84^{\star *}$ & $12.76^{* *}$ & $4.43^{\star \star}$ & $7.40^{* *}$ \\
\hline Error variance & 18.97 & 2.73 & 0.75 & 2.28 & 0.05 & 1.18 & 158.94 & 383,933 \\
\hline Overall mean & 69 & 12.9 & 3.62 & 6.18 & 1.34 & 13.7 & 71.1 & 2,233 \\
\hline Mean male-sterile lines & 56.17 & 9.96 & 1.11 & 3.63 & 1.66 & 14.09 & 49.6 & 622 \\
\hline Mean restorer lines and hybrids & 69.2 & 13.1 & 3.8 & 6.4 & 1.32 & 13.7 & 72.6 & 2,348 \\
\hline Accuracy & 0.76 & 0.88 & 0.93 & 0.88 & 0.86 & 0.96 & 0.88 & 0.93 \\
\hline
\end{tabular}

EXT, juice extraction (\%); TSS, total soluble solid content (\% juice); TBH, tons of brix per hectare; POLc, sucrose content (\% stalk); RSc, reducing sugar content (\% stalk); FIBER, stalk fiber content (\%); TRS, total recoverable sugars (kg/t stalk); and ETP, ethanol production per hectare (L/ha). **indicates significant difference by Snedecor's F-test at the $1 \%$ probability level.

Table 3. Phenotypic (above diagonal) and environmental (below diagonal) correlations of agronomic and technological traits of 45 sweet sorghum genotypes evaluated in Lavras city in the 2012/2013 growing season.

\begin{tabular}{|c|c|c|c|c|c|c|c|c|c|c|c|c|}
\hline & FLOWER & $\mathrm{PH}$ & PM & TSH & EXT & TSS & TBH & Polc & RSc & Fiber & TRS & ETP \\
\hline FLOWER & 1 & $0.35^{* *}$ & $-0.27^{*}$ & $0.72^{* *}$ & 0.01 & $0.64^{* *}$ & $0.77^{* *}$ & $0.65^{\star *}$ & $-0.47^{* *}$ & -0.18 & $0.66^{* *}$ & $0.75^{\star *}$ \\
\hline $\mathrm{PH}$ & 0.23 & 1 & 0.25 & $0.66^{\star \star}$ & -0.07 & $0.56^{\star \star}$ & $0.58^{\star \star}$ & $0.51^{* \star}$ & $-0.51^{* *}$ & 0.18 & $0.50^{\star \star}$ & $0.57^{\star *}$ \\
\hline PM & 0.07 & 0.08 & 1 & 0.01 & $-0.26^{\star}$ & -0.18 & -0.14 & -0.22 & 0.06 & $0.30^{*}$ & -0.24 & -0.12 \\
\hline TSH & 0.09 & 0.22 & 0.07 & 1 & -0.02 & $0.65^{\star \star}$ & $0.93^{* *}$ & $0.63^{* *}$ & $-0.49^{* *}$ & -0.10 & $0.64^{* \star}$ & $0.89^{* *}$ \\
\hline EXT & 0.09 & -0.15 & 0.05 & -0.05 & 1 & -0.20 & -0.04 & -0.17 & $0.37^{\star *}$ & $-0.68^{* *}$ & -0.14 & -0.17 \\
\hline TSS & 0.14 & 0.11 & -0.11 & 0.17 & -0.17 & 1 & $0.84^{\star *}$ & $0.98^{\star *}$ & $-0.88^{* *}$ & 0.16 & $0.98^{* *}$ & $0.86^{\star *}$ \\
\hline TBH & 0.06 & 0.18 & -0.06 & $0.80^{++}$ & -0.14 & $0.64^{++}$ & 1 & $0.79^{\star *}$ & $-0.64^{* *}$ & -0.06 & $0.81^{\text {** }}$ & $0.98^{* *}$ \\
\hline Polc & 0.24 & 0.07 & -0.16 & 0.14 & -0.21 & $0.80^{++}$ & $0.49^{++}$ & 1 & $-0.91^{* *}$ & 0.05 & $0.99^{\star \star}$ & $0.87^{\star \star}$ \\
\hline RSc & -0.24 & -0.07 & 0.05 & -0.14 & 0.13 & $-0.67^{++}$ & $-0.38^{++}$ & $-0.90^{++}$ & 1 & $-0.34^{*}$ & $-0.88^{* *}$ & $-0.74^{\star \star}$ \\
\hline Fiber & 0.001 & 0.11 & -0.13 & 0.09 & 0.02 & 0.10 & 0.09 & -0.03 & -0.05 & 1 & 0.01 & 0.06 \\
\hline TRS & 0.24 & 0.07 & -0.17 & 0.13 & -0.22 & $0.81^{++}$ & $0.50^{++}$ & $0.99^{++}$ & $-0.87^{++}$ & -0.04 & 1 & $0.87^{* *}$ \\
\hline ETP & 0.13 & 0.19 & -0.14 & $0.70^{++}$ & -0.26 & $0.64^{++}$ & $0.88^{++}$ & $0.70^{++}$ & $-0.58^{++}$ & 0.19 & $0.71^{++}$ & 1 \\
\hline
\end{tabular}

FLOWER, flowering time (days); PH, plant height (m); PM, panicle mass (g): TSH, tons of stalk per hectare; EXT, juice extraction (\%); TSS, total soluble solid content (\% juice); TBH, tons of brix per hectare; Polc, apparent sucrose content (\% stalk); RSc, reducing sugar content (\% stalk); FIBER, stalk fiber content (\%); TRS, total amount of reduced sugars (kg/t stalk); and ETP, ethanol production per hectare (L/ha). *and **indicate significant differences by the bootstrap test at the 5 and $1 \%$ probability levels, respectively. ${ }^{+}$Significant difference by Student's t-test at the $1 \%$ probability level.

\section{Path analysis}

In the present study, we developed a causal diagram with two chains (Figure 1). The explanatory variables in the diagram offer a coherent explanation of ethanol production per hectare (Tables 4, 5 and 6).

Among the primary causal variables, TBH had a higher positive direct effect over the main variable ETP (Table 4). In the same way, the trait TBH presented high positive correlation with ETP (Table 3). Therefore, our analysis indicated that indirect selection for ETP from TBH is feasible.

The traits RSc, TRS, and POLc did not show direct effects on ethanol production per hectare (Table 4). However, they influenced indirectly the ethanol production due to high effects via TBH.

When considering the effects of secondary variables on primary variables, we observed that they did not satisfactorily explain all the variation in the primary traits (Table 5). The trait FLOWER had a positive direct effect on TBH (Table 5).

With regard to the effects of secondary traits on ethanol production per hectare, only the traits FLOWER and plant height $(\mathrm{PH})$ showed secondary direct effects via TBH (Table 6). Higher magnitude effects of secondary traits over ETP were seen for the indirect effect of FLOWER via PH and the indirect effect of $\mathrm{PH}$ via FLOWER, both through the association with TBH. Hence, these secondary effects were compatible with the estimates of a correlation of 0.75 between FLOWER and ETP and of 0.57 between PH and ETP (Table 3). 
Table 4. Estimates of direct and indirect effects of the primary variables on the main variable ethanol production per hectare (ETP) measured in 45 sweet sorghum genotypes grown in Lavras city in the 2012/2013 growing season

\begin{tabular}{|c|c|c|}
\hline Primary variable & Association path & Path coefficient \\
\hline \multirow[t]{6}{*}{ TBH } & Direct effect over ETP & 0.698 \\
\hline & Indirect effect via EXT & 0.003 \\
\hline & Indirect effect via Polc & 0.109 \\
\hline & Indirect effect via RSc & -0.003 \\
\hline & Indirect effect via TRS & 0.126 \\
\hline & Total & 0.976 \\
\hline \multirow[t]{6}{*}{ EXT } & Direct effect over ETP & -0.090 \\
\hline & Indirect effect via TBH & -0.026 \\
\hline & Indirect effect via Polc & -0.024 \\
\hline & Indirect effect via RSc & 0.002 \\
\hline & Indirect effect via TRS & -0.022 \\
\hline & Total & -0.166 \\
\hline \multirow[t]{6}{*}{ Polc } & Direct effect over ETP & 0.138 \\
\hline & Indirect effect via TBH & 0.554 \\
\hline & Indirect effect via EXT & 0.016 \\
\hline & Indirect effect via RSc & -0.004 \\
\hline & Indirect effect via TRS & 0.156 \\
\hline & Total & 0.868 \\
\hline \multirow[t]{6}{*}{ RSc } & Direct effect over ETP & 0.004 \\
\hline & Indirect effect via TBH & -0.444 \\
\hline & Indirect effect via EXT & -0.033 \\
\hline & Indirect effect via Polc & -0.125 \\
\hline & Indirect effect via TRS & -0.138 \\
\hline & Total & -0.736 \\
\hline \multirow[t]{6}{*}{ TRS } & Direct effect over ETP & 0.156 \\
\hline & Indirect effect via TBH & 0.562 \\
\hline & Indirect effect via EXT & 0.013 \\
\hline & Indirect effect via Polc & 0.137 \\
\hline & Indirect effect via RSc & -0.004 \\
\hline & Total & 0.874 \\
\hline $\mathrm{R}^{2}(\%)$ & & 94.88 \\
\hline Residual effect & & 0.226 \\
\hline
\end{tabular}

TBH, tons of brix per hectare; EXT, juice extraction from stalk; Polc, sucrose; RSc, reducing sugar; TRS, total reducing sugar; ETP, ethanol production per hectare.

Table 5. Estimates of the direct and indirect effects of secondary variables on primary variables in 45 sweet sorghum genotypes grown in Lavras city in the 2012/2013 growing season.

\begin{tabular}{|c|c|c|c|c|c|}
\hline \multirow[t]{2}{*}{ Description of effects } & \multicolumn{5}{|c|}{ Primary variables } \\
\hline & TBH & EXT & Polc & RSc & TRS \\
\hline Secondary direct effect of FLOWER & 0.59 & -0.18 & 0.46 & -0.35 & 0.47 \\
\hline Indirect effect of FLOWER via PH & 0.13 & 0.05 & 0.12 & -0.12 & 0.12 \\
\hline Indirect effect of FLOWER via PM & 0.02 & 0.04 & 0.05 & -0.04 & 0.06 \\
\hline Indirect effect of FLOWER via Fiber & 0.00 & 0.12 & -0.02 & 0.07 & -0.02 \\
\hline Total & 0.77 & 0.01 & 0.65 & -0.47 & 0.66 \\
\hline Secondary direct effect of $\mathrm{PH}$ & 0.37 & 0.13 & 0.35 & -0.34 & 0.35 \\
\hline Indirect effect of PH via FLOWER & 0.20 & -0.06 & 0.16 & -0.12 & 0.16 \\
\hline Indirect effect of PH via PM & -0.02 & -0.03 & -0.05 & 0.04 & -0.05 \\
\hline Indirect effect of $\mathrm{PH}$ via Fiber & 0.00 & -0.12 & 0.02 & -0.07 & 0.02 \\
\hline Total & 0.58 & -0.07 & 0.51 & -0.51 & 0.50 \\
\hline Secondary direct effect of PM & -0.07 & -0.13 & -0.20 & 0.15 & -0.21 \\
\hline Indirect effect of PM via FLOWER & -0.16 & 0.05 & -0.13 & 0.10 & -0.13 \\
\hline Indirect effect of PM via PH & 0.09 & 0.03 & 0.09 & -0.08 & 0.09 \\
\hline Indirect effect of PM via Fiber & 0.00 & -0.20 & 0.04 & -0.11 & 0.03 \\
\hline Total & -0.14 & -0.26 & -0.22 & 0.06 & -0.24 \\
\hline Secondary direct effect of Fiber & 0.00 & -0.66 & 0.12 & -0.37 & 0.08 \\
\hline Indirect effect of Fiber via FLOWER & -0.11 & 0.03 & -0.09 & 0.06 & -0.09 \\
\hline Indirect effect of Fiber via PH & 0.07 & 0.02 & 0.06 & -0.06 & 0.06 \\
\hline Indirect effect of Fiber via PM & -0.02 & -0.04 & -0.06 & 0.05 & -0.06 \\
\hline Total & -0.06 & -0.68 & 0.05 & -0.34 & 0.00 \\
\hline \multicolumn{6}{|l|}{$\mathrm{R}^{2}(\%)$} \\
\hline \multirow[t]{2}{*}{ Residual effect } & 68 & 47 & 53 & 48 & 54 \\
\hline & 0.57 & 0.73 & 0.69 & 0.72 & 0.68 \\
\hline
\end{tabular}

FLOWER, days to flowering; PH, plant height; PM, panicle mass; TBH, tons of brix per hectare; EXT, juice extraction from stalk; Polc, sucrose; RSc, reducing sugar; TRS, total reducing sugar. 
Table 6. Estimates of direct and indirect effects of secondary variables on ethanol production per hectare (ETP) in 45 sweet sorghum genotypes grown in Lavras city in the 2012/2013 growing season.

\begin{tabular}{|c|c|c|c|c|c|c|c|}
\hline \multirow[t]{2}{*}{ Description of effects } & \multicolumn{5}{|c|}{ Primary variables } & \multirow[t]{2}{*}{ Residual effect } & \multirow{2}{*}{$\begin{array}{c}\text { Total effect } \\
\text { ETP }\end{array}$} \\
\hline & TBH & EXT & Polc & RSc & TRS & & \\
\hline Secondary direct effect of FLOWER & 0.41 & 0.02 & 0.06 & 0.00 & 0.07 & 0.03 & 0.60 \\
\hline Indirect effect of FLOWER via PH & 0.09 & 0.00 & 0.02 & 0.00 & 0.02 & 0.00 & 0.12 \\
\hline Indirect effect of FLOWER via PM & 0.01 & 0.00 & 0.01 & 0.00 & 0.01 & 0.00 & 0.02 \\
\hline Indirect effect of FLOWER via Fiber & 0.00 & -0.01 & 0.00 & 0.00 & 0.00 & -0.01 & -0.02 \\
\hline Total & 0.54 & 0.00 & 0.09 & 0.00 & 0.10 & 0.02 & 0.75 \\
\hline Secondary direct effect of $\mathrm{PH}$ & 0.26 & -0.01 & 0.05 & 0.00 & 0.05 & -0.01 & 0.34 \\
\hline Indirect effect of PH via FLOWER & 0.14 & 0.01 & 0.02 & 0.00 & 0.03 & 0.01 & 0.21 \\
\hline Indirect effect of PH via PM & -0.01 & 0.00 & -0.01 & 0.00 & -0.01 & 0.00 & -0.02 \\
\hline Indirect effect of $\mathrm{PH}$ via Fiber & 0.00 & 0.01 & 0.00 & 0.00 & 0.00 & 0.01 & 0.02 \\
\hline Total & 0.41 & 0.01 & 0.07 & 0.00 & 0.08 & 0.01 & 0.57 \\
\hline Secondary direct effect of PM & -0.05 & 0.01 & -0.03 & 0.00 & -0.03 & 0.01 & -0.08 \\
\hline Indirect effect of PM via FLOWER & -0.11 & -0.01 & -0.02 & 0.00 & -0.02 & -0.01 & -0.16 \\
\hline Indirect effect of PM via PH & 0.06 & 0.00 & 0.01 & 0.00 & 0.01 & 0.00 & 0.08 \\
\hline Indirect effect of PM via Fiber & 0.00 & 0.02 & 0.01 & 0.00 & 0.00 & 0.01 & 0.04 \\
\hline Total & -0.10 & 0.02 & -0.03 & 0.00 & -0.04 & 0.02 & -0.13 \\
\hline Secondary direct effect of Fiber & 0.00 & 0.06 & 0.02 & -0.00 & 0.01 & 0.04 & 0.13 \\
\hline Indirect effect of Fiber via FLOWER & -0.08 & 0.00 & -0.01 & 0.00 & -0.02 & -0.01 & -0.11 \\
\hline Indirect effect of Fiber via PH & 0.05 & 0.00 & 0.01 & 0.00 & 0.01 & 0.00 & 0.06 \\
\hline Indirect effect of Fiber via PM & -0.01 & 0.01 & -0.01 & 0.00 & -0.01 & 0.00 & -0.03 \\
\hline Total & -0.04 & 0.06 & 0.01 & 0.00 & 0.00 & 0.04 & 0.07 \\
\hline
\end{tabular}

FLOWER, days to flowering; $\mathrm{PH}$, plant height; $\mathrm{PM}$, panicle mass; $\mathrm{TBH}$, tons of brix per hectare; EXT, juice extraction from stalk; Polc, sucrose; RSc, reducing sugar; TRS, total reducing sugar.

\section{DISCUSSION}

The ideal genotype of sweet sorghum should show good agronomic performance and high juice yield. The overall means for agronomic traits (Table 1) were similar to those reported by Almodares et al. (2009) and Souza et al. (2013). For technological traits (Table 2), the overall means were lower than those obtained by Almodares et al. (2009) and Regassa et al. (2014). This difference was probably due to the inclusion here of male-sterile plants, which had a lower performance than restorer lines and hybrids.

To select superior genotypes considering multiple traits is so important to estimate the correlations. The target trait in sweet sorghum breeding is ethanol production per hectare (ETP). The knowledge of the correlations it is possible to design new strategies for selection (e.g. indirect selection), since that major causes of the phenotypic correlations be associated with linked or pleiotropic genes (Falconer and Mackay, 1996). According to Reddy et al. (2005), low panicle mass is associated with higher TSS, TRS, and POLc production, which are desirable for ethanol production. However, in the present study there were no significant correlations between panicle mass and the technological traits associated with sugar content. It was observed from the simple phenotypic correlations, that it is feasible to propose indirect selection to increase the ethanol production from the traits FLOWER, TSH e TSS which are easily measurable. This result for TSS is contrary to that reached by Kumar et al. (2012).

Although these simple correlations are useful in plant breeding, the information is restricted to pairs of traits. Additionally, these estimates may not represent the true level of association between traits, since it is possible that a third character, or group of traits, might influence the observed association (Chaudhary et al., 1973). Consequently, path analysis offers a valuable alternative approach (Wright, 1921) as it allows a detailed study of the association of a group of traits.

The first and essential step in path analysis is to prepare a causal diagram (Wright, 1921; 
Kozak and Kang, 2006). The path analysis indicated that TBH had the highest direct effect and that selection for this trait to increase ETP is feasible. Therefore, the trait TBH may work as a practical and efficient indicator for selection, linking information on agronomic and technological potential (Guigou et al., 2011).

Additionally, the analysis suggested that selection for the traits FLOWER and PH might offer a good strategy to increase the genetic gain in ETP in a sweet sorghum breeding program. This conclusion is consistent with a previous study (Kumar et al., 2012).

\section{Conflicts of interest}

The authors declare no conflict of interest.

\section{ACKNOWLEDGMENTS}

Authors are grateful to Embrapa Maize and Sorghum and all collaborators of the trials network of sweet sorghum, and to financial support of National Counsel of Technological and Scientific Development - CNPq, Brazilian Federal Agency for Support and Evaluation of Graduate Education - CAPES and Minas Gerais State Research Foundation - FAPEMIG.

\section{REFERENCES}

Almodares A and Hadi MR (2009). Production of bioethanol from sweet sorghum: a review. African J. Agricult. Res. 4: 772-780. AOAC (Association of Official Analytical Chemists) (1990). Official methods of analysis.15th edn. AOAC, Washington.

Bovi R and Serra GE (2001). Folhas verdes, folhas secas, fibra do colmo e clarificação do caldo de cana-de-açúcar. Sci. agric. 58: $72-80$

Carvalho SP and Cruz CD (1996). Diagnosis of multicollinearity: assessment of the condition of correlation matrices used in genetic studies. Brazilian J. Genet. 19: 479-484.

Chaudhary D, Srivasta SP, Ghosh AK and Seethara R (1973). Genetic variability and correlation for yield components in rice. Indian J. Agricult. Sci. 43:181-184.

Chaudhary RR and Joshi BK (2005). Correlation and path coefficient analyses in sugarcane. Nepal Agric. Res. J. 6: 24-27.

CONSECANA (2006). Conselho dos produtores de cana-de-açúcar, açúcar e álcool do estado de São Paulo. Manual de instruções. $5^{\text {th }}$ edn. Piracicaba.

Cruz CD (2013). GENES - a software package for analysis in experimental statistics and quantitative genetics. Acta Scient. 35: 271-276

EPE (2011). Balanço Energético Nacional, 2011. Available at [https://ben.epe.gov.br/downloads/Relatorio_Final_BEN_2011. pdf]. Accessed May 9, 2014.

Espósito DP, Peternelli LA, Paula TOM and Barbosa MHP (2012). Análise de trilha usando valores fenotípicos e genotípicos para componentes do rendimento na seleção de famílias de cana-de-açúcar. Cienc. Rural 42: 38-44.

Falconer DS and Mackay TFC (1996). Introduction to quantitative genetics. $4^{\text {th }}$ edn. Longman Group Limited, Edinburgh.

Guigou M, Lareo C, Pérez LV, Lluberas ME, et al. (2011). Bioethanol production from sweet sorghum: evaluation of postharvest treatments on sugar extraction and fermentation. Biomass Bioenergy 35: 3058-3062.

Kim M and Day DF (2010). Composition of sugar cane, energy cane, and sweet sorghum suitable for ethanol production at Louisiana sugar mills. J. Ind. Microbiol. Biotechnol. 38: 803-807.

Kozak M and Kang MS (2006). Note on modern path analysis in application to crop science. Commun. Biometry Crop Sci. 1: 32-34.

Kumar CVS, Umakanth AV, Kotastane TV and Sreelakshmi CH (2012).Character association and path analysis for qualitative traits in sweet sorghum (Sorghum bicolor L. Moench). J. Res. ANGRAU 40: 90-93.

Littel RC, Milliken GA, Stroup WW, Wolfinger RD, et al. (2006). SAS for Mixed Models. 2nd edn. SAS Institute Inc., Cary, NC, USA.

Milanez AY, NykoD, Garcia JLF and Reis BLSFS (2012). O deficit de produção de etanol no Brasil entre 2012 e 2015: determinantes, consequências e sugestões de política. Biocombustíveis. BNDS Setorial 35: 277-302.

Montgomery DC and Peck EA (1981). Introduction to linear regression analysis. J. Wiley, New York.

Mundim GB, Viana JMS, Maia C, Paes GP, et al. (2013). Genetic diversity and path analysis for nitrogen use efficiency in 
popcorn inbred lines. Euphytica 191: 291-299

Ramalho MAP, Santos JB and Zimmermann MJ (1993). Genética quantitativa em plantas autógamas: aplicações ao melhoramento do feijoeiro. Goiânia: UFG.

Reddy B, Ramesh S, Reddy S, Ramaiah B, et al. (2005). Sweet sorghum - a potential alternate raw material for bio-ethanol and bio-energy.Int. Sorghum Millets Newslett. 46: 79-86.

Regassa TH and Wortmann CS (2014). Sweet sorghum as a bioenergy crop: literature review. Biomass Bioenergy 13: 1-8.

Resende MDV and Duarte JB (2007). Precisão e controle de qualidade em experimentos de avaliação de cultivares. Pes. Agropec. Tropical 37: 182-194.

SAS (2012). System requirements for SAS 9.3 foundation for Microsoft Windows for x64. SAS Institute Inc., Cary, NC, USA.

Singh RK, Singh SP and Singh SB (2005). Correlation and path analysis in sugarcane Ratoon. Sugarcane Research Institute, Shahjahanpur, 242 001, U.P., India: 176-178.

Souza VF, Parrella RAC, Tardin FD, Costa MR, et al. (2013). Adaptabilidade e estabilidade de cultivares de sorgo sacarino. Crop Breeding Appl. Biotechnol. 13: 144-151.

Teixeira DHL, Oliveira MSP, Gonçalves FMA and Nunes JAR (2012). Correlações genéticas e análise de trilha para componentes da produção de frutos de açaizeiro. Rev. Bras. Frutic. 34: 1135-1142.

Wright S (1921).Correlation and causation. J. Agric. Res. 20: 557-585. 